\title{
FERROCARRILES Y SOBERANÍA: EL FERROCARRIL DE PANAMÁ, 1850-1903*
}

\author{
RAILROADS AND SOVEREIGNTY: THE PANAMA \\ RAILROAD, 1850-1903
}

\author{
Juan Santiago Correa R. \\ Colegio de Estudios Superiores de Administración, Bogotá, Colombia, juansc@cesa.edu.co
}

Resumen. Este artículo estudia el proceso de construcción y operación del Ferrocarril de Panamá, el cual se constituyó como un proyecto pionero en el desarrollo ferroviario colombiano a mediados del siglo XIX, brindando los elementos arquetípicos de las concesiones férreas en este país, así como los mecanismos para atraer la inversión extranjera. Sin embargo, a pesar de los beneficios comerciales y fiscales para Colombia, el ferrocarril se convirtió en uno de los elementos centrales de reto a la soberanía nacional y una de las claves para entender el proceso de secesión de Panamá en 1903.

Palabras clave: ferrocarriles; inversión extranjera; soberanía; doctrina Monroe.

Abstract. This article analyzes the construction and operation of the Panama Railroad. This was a pioneer project in the Colombian railway development in the nineteenth century, which helped to define some of the basic characteristics on the railway concession contracts in this country, as well as the mechanism to attract foreign investment. However, despite the benefits to the global trade and fiscal benefits obtained from Colombia, the railroad became a central element of challenge to national sovereignty, and one of the key elements in the process that led to the secession of Panama in 1903.

Key words: railways; foreign investment; sovereignty; Monroe doctrine.

Fecha de recepción: 9 de julio de 2013. Fecha de aceptación: 18 de junio de 2014.

\footnotetext{
* Versiones previas de este artículo fueron presentadas en el Congreso Internacional de Americanistas (México, 2009), XV Congreso Colombiano de Historia (Bogotá, 2010), I Congreso Internacional de la Asociación de Historia Económica (Santa Marta, 2011), Congreso de la British Academy of Managment (Cardiff, 2012) y World Business History Conference (Frankfurt, 2014). $\mathrm{El}$ autor expresa su gratitud a las personas que han realizado comentarios y retroalimentación a las versiones preliminares de este artículo y a los comentarios recibidos en un artículo previo publicado en la revista Estudios Gerenciales, cuyo objetivo principal fue el de estudiar el proceso de inversión de Estados Unidos en el Ferrocarril de Panamá entre 1850 y 1869.
} 


\section{INTRODUCCIÓN}

$\mathrm{L}$

os cambios provocados por la revolución industrial tuvieron como consecuencia modificaciones de fondo en las dinámicas económicas y políticas del mundo. Estos cambios fueron acompañados de transformaciones políticas en América, con las que el Estado-nación se convirtió en la forma de organización política hegemónica. Bajo las nuevas condiciones económicas del mundo, los países latinoamericanos generalmente basaron sus economías en actividades extractivas y agrícolas para articular de manera asimétrica las economías regionales con las nuevas dinámicas de comercio exterior. Dichas economías dependían de las de otros países, primero de España y, después de la independencia, de Gran Bretaña.

No obstante, la Panama Railroad Company fue una iniciativa que anticipó casi dos décadas la construcción de ferrocarriles en Colombia y tuvo características diferentes, en la medida en que no buscó conectar núcleos de producción local con los mercados externos. El Ferrocarril de Panamá no fue el único diseñado como una ruta de tránsito ni como un eje articulador de centros de producción con los mercados internacionales. Aunque empresas similares pueden encontrarse en otros países de Latinoamérica, la comparación con estas sobrepasa los límites de este artículo.

Operativamente, se convirtió durante parte de su historia como una empresa rentable, y reflejó de manera clara los intereses económicos y políticos de Estados Unidos, no sólo frente a Latinoamérica, sino con sus competidores más fuertes en la región: Francia, Inglaterra y España. La empresa creó uno de los monopolios de transporte más importantes de la época y significó uno de los recursos fiscales más valorados por el gobierno colombiano.

Su temprano desarrollo se debió, probablemente, a que la Constitución de 1863 presentó una modificación importante en relación con las anteriores, ya que restringía al gobierno nacional llevar a cabo inversiones de fomento en comunicación e infraestructura de todo proyecto que no tuviera relevancia nacional. Esto implicó que los fondos federales sólo podían ser destinados a la mejora o formación de medios de transporte interoceánicos, ríos que comunicaran a más de un Estado soberano ${ }^{1}$ o que sirvieran a las fronteras del país. Sólo hasta 1872 el legislativo retiró estas restricciones y abrió la posibilidad de subsidios a la construcción de ferrocarriles, los cuales fueron financiados en parte con un incremento de los impuestos aduaneros en 1873, que llegó en 1874 hasta 25\% (Horna, 2003, p. 1023).

${ }^{1}$ La Constitución de 1863 convirtió a Colombia en un Estado federal en extremo descentralizado y, en consecuencia, cada una de sus divisiones administrativas se definió como Estado soberano. 
En la historiografía sobre el Ferrocarril de Panamá se han trabajado con suficiencia los aspectos técnicos y operativos del funcionamiento de la línea desde su inicio hasta la actualidad, en particular el minucioso texto de Hull (1999). Sin embargo, poco se ha trabajado la relación que tuvo este ferrocarril con la dinámica política dentro de Panamá, con Colombia, con grupos empresariales transnacionales y con las grandes potencias económicas y militares que buscaban apuntalar su presencia en el Caribe, así como en la relación entre el capital externo y el surgimiento de Panamá como Estado y la pérdida de soberanía de Colombia sobre el istmo. El presente artículo pretende ser un aporte en este sentido. Es importante anotar que las intenciones separatistas panameñas tienen profundas raíces en el siglo XIX y no es posible explicar la separación desde una perspectiva unidimensional. Aunque este artículo se concentra en las relaciones mencionadas, por supuesto estas son sólo una parte de lo que lleva a la secesión en 1903.

El texto se ha divido en cuatro secciones. En la primera se estudia el proceso mediante el cual se ideó una ruta transcontinental en el istmo y las razones por las cuales sólo se concretó con la Panama Railroad Company; en la segunda se analizan los mecanismos mediante los que la inversión extranjera pudo llevar a cabo el proyecto hasta su puesta en marcha; en la tercera se examinan las tensiones entre los diferentes intereses regionales, nacionales y extranjeros sobre el istmo y su eventual injerencia en la separación de Panamá; por último, se presentan las consideraciones finales.

\section{LA IDEA DE UNA RUTA TRANSCONTINENTAL}

El Ferrocarril de Panamá puede considerarse un caso atípico en la construcción de ferrocarriles en Latinoamérica y, en especial, en Colombia. En primer lugar, fue el primero en ser construido con el expreso propósito de atravesar el continente; ${ }^{2}$ en segundo lugar, no conectó ningún centro de producción local con el mercado internacional (Platt, 1926, p. 16); tercero, la inversión fue realizada exclusivamente por el capital extranjero; cuarto, fue en términos generales una empresa rentable, al menos mientras mantuvo el monopolio en los trayectos intercontinentales en América (Arias de Greiff, 1986, p. 13).

Esto ocurrió durante el marco de expansión territorial de Estados Unidos hacia el oeste por una rápida sucesión de anexiones de los territorios de Texas en 1845; California, tras una guerra entre 1846 y 1848, y Nue-

\footnotetext{
${ }^{2}$ Más adelante sería seguido por otros proyectos como la conexión del Central Pacific con el Union Pacific en Estados Unidos o el Ferrocarril de Tehuantepec en México.
} 
vo México y Arizona en 1848. Así, México perdió todos los territorios que iban al norte del río Grande y los que quedaban al norte de la línea formada entre El Paso, Texas, y San Diego, California; de esta forma, la consolidación de la expansión hacia el oeste y el sur se instauró de manera definitiva con las oportunidades económicas que esto significaba (Weaver, 1992, pp. 153-155).

El principal problema de estas anexiones, en particular de la costa oeste, era la comunicación. El transporte de mercancías, personas y correo presentaba dificultades mayores debido a que el tránsito a través del continente era difícil, en carretas o a pie, por terrenos complicados e incluso sin cartografiar y, en muchas regiones, por zonas controladas por comunidades indígenas hostiles a dicha expansión. El trayecto por mar tampoco era sencillo, pues implicaba un viaje al sur del continente por el peligroso Cabo de Hornos. Sin embargo, el descubrimiento de oro en California, poco después de su anexión, trajo un incentivo adicional, difícil de no tener en cuenta por parte del gobierno federal y de los inversionistas estadunidenses (Sánchez, 2002, p. 63).

Frente a estas necesidades, el gobierno neogranadino firmó en 1843 el tratado Mallarino-Bidlack con Estados Unidos, en el que Colombia obtenía la seguridad de neutralidad y el reconocimiento de la soberanía sobre Panamá; a cambio, los ciudadanos y el gobierno estadunidenses obtuvieron derechos de tránsito a través del istmo. El político liberal Salvador Camacho Roldán estimó que el volumen de pasajeros aumentó entre 25000 y 40000 viajeros anuales a través del istmo, a un total de 375000 en tránsito hacia el sur, y a alrededor de 225000 hacia el norte; esto entre 1848 y 1869 (Pérez, 2007, p. 151).

Uno de los puntos más importantes del tratado Mallarino-Bidlack fue el derecho que se otorgó al gobierno de Estados Unidos para transportar cualquier artículo o mercancía con paso franco por el istmo. En particular, esta cláusula fue muy atractiva para el United States Post Service, ya que necesitó una vía más segura y eficiente que la alternativa terrestre o la peligrosa ruta del Cabo de Hornos. Estos incentivos generaron interés en tres inversionistas estadunidenses. El 28 de diciembre de 1848, John Stephens, William Aspinwall y Henry Chauncey firmaron un contrato en Washington con Pedro Alcántara Herrán, en nombre del gobierno de José Hilario López, para la construcción de una línea férrea transcontinental, misma que se trataba, como se discutirá más adelante, de la Panama Railroad Company (Board of Directors, 1849, pp. 29-54).

La compañía se constituyó con un capital suscrito de 5000000 de dólares, divididos en 50000 acciones de 100 dólares cada una, los cuales se fueron aportando durante la construcción en la medida en que esta avanzaba. Así, para 1852 el capital pagado ascendió a 1467720 dólares, en 
1853 a 2716572 dólares, en 1854 a 2875000 dólares, en 1855 a 4532000 dólares, en 1862 llegó a 4981000 dólares y en 1865 el capital suscrito y pagado se elevó a 7000000 de dólares. Para enfrentar los gastos de construcción y operación, la compañía obtuvo un crédito en libras por el equivalente a 4300000 dólares con un interés de 3.5\% (Pérez, 2007, p. 155).

La Panama Railroad Company obtuvo los derechos exclusivos de la construcción de la línea, la administración de los puertos situados en los dos extremos, derechos exclusivos para la construcción de un futuro canal, una cesión importante de terrenos para construir la línea, los puertos, los almacenes, el derecho de posesión de las tierras en la isla de Manzanillo y 150000 fanegadas $^{3}$ a perpetuidad en las provincias de Panamá y Veraguas; además de la exención de los derechos de importación de todos los materiales necesarios para la construcción. A cambio de esto, el gobierno colombiano recibía $5 \%$ de lo producido por el correo y $3 \%$ de los beneficios netos en la misma proporción de la repartición de los dividendos distribuidos por la empresa. Colombia tenía la prerrogativa para redimir la obra por 5000000 de dólares al cabo de 20 años, 4000000 a los 30 años y a los 40 años por 2000000 (Cavalier, 1960, p. 65).

\section{INVERSIÓN EXTRANJERA Y LA CONSTRUCCIÓN DE LA LÍNEA FÉRREA}

Una vez que la Panama Railroad Company se estableció en Nueva York, las visitas técnicas realizadas y el contrato firmado, la empresa tuvo que enfrentar el reto de la construcción. La idea inicial pretendía comenzar el tendido de rieles desde el mar Caribe a partir de Gorgona, un caserío entre Chagres y Cruces, con la intención de utilizar el río Chagres como vía para barcos de vapor de bajo calado como apoyo a la construcción (McGuinness, 2008, p. 56). El problema de esta idea consistía en las variaciones permanentes del caudal del río, lo que impedía un servicio regular.

La empresa, luego de un proceso licitatorio, comisionó a George M. Totten y John G. Trautwine para la construcción de la línea férrea; estos tomaron la decisión de mover unos cuantos kilómetros el tendido de la ruta hacia el este de la bahía de Limón, en la isla de Manzanillo, donde se establecieron los primeros cuarteles (McGuinness, 2008, p. 58) (véase mapa 1). Las dificultades de conseguir materiales para la construcción se hicieron evidentes desde el comienzo, incluso se tuvieron que importar las primeras barracas de madera desde Nueva Orleans (Hull, 1999, p. 8).

\footnotetext{
${ }^{3}$ En Colombia se entiende la fanegada como un cuadrado de 80 metros de lado y un total de 6400 metros cuadrados.
} 


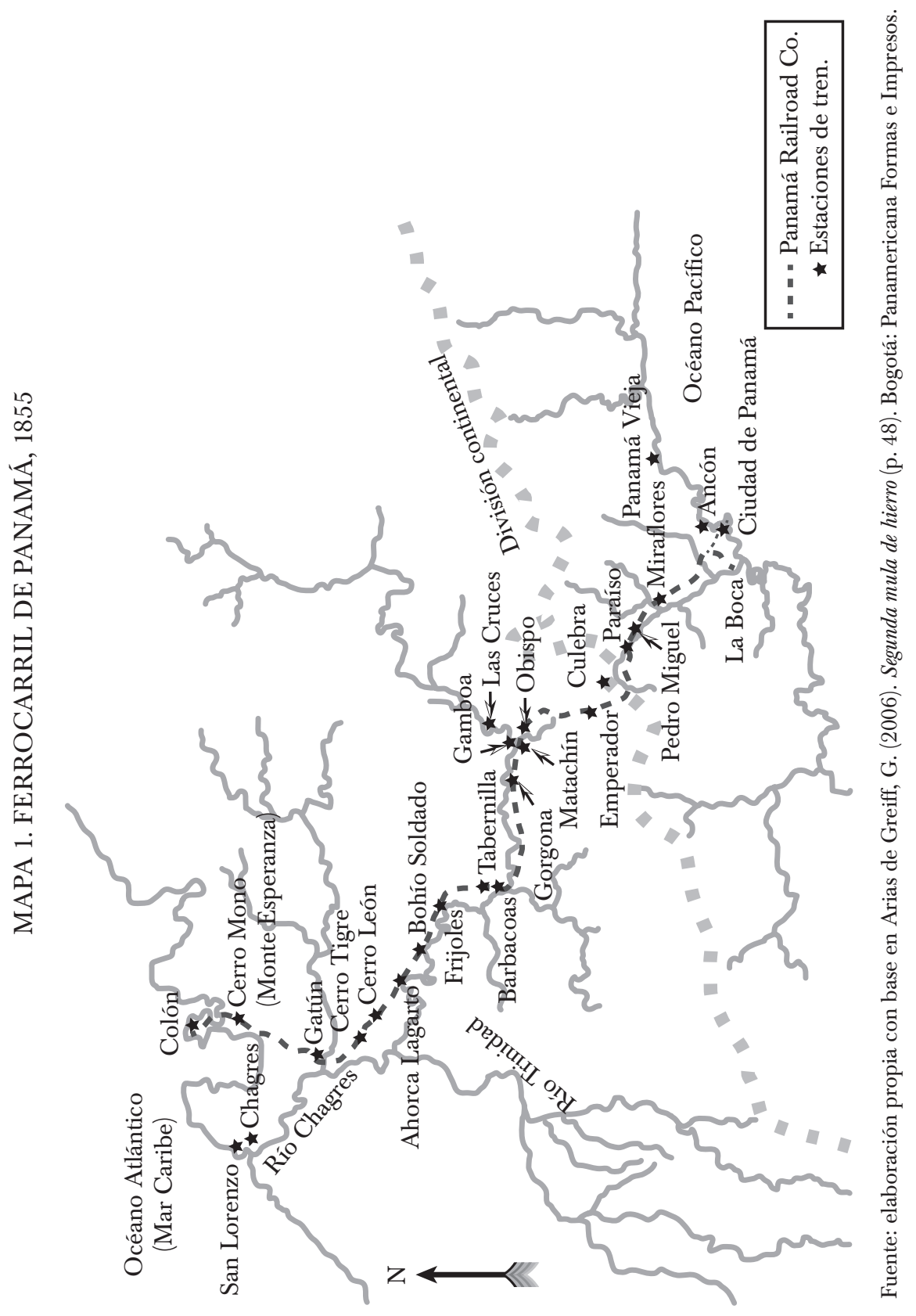


Rápidamente, la isla de Manzanillo vivió un proceso acelerado de poblamiento por parte de la compañía, que se reflejó en la construcción de almacenes, casas de juego, barracas y los muelles necesarios para recibir los materiales y el personal requerido. La compañía llamó a este poblado Aspinwall, pero el gobierno colombiano rechazó este nombre y la denominó Colón; unos y otros utilizaron ambos nombres durante casi 40 años hasta que Correos de Colombia se negó a entregar correspondencia dirigida al poblado de Aspinwall, a partir de 1890 sólo se conoció con el nombre de Colón (Hull, 1999, p. 10; Oran [1858], 2004, p. 23) .

La construcción se inició en agosto de 1850 alrededor de Cerro Mono, más adelante conocido como Monte Esperanza, una zona de cuatro millas pantanosas que hizo que la llegada al río Chagres y el poblado indígena de Gatún fuera muy complicada. No obstante, luego de haber construido siete millas, Totten informó a los inversionistas que el dinero se había terminado, una inversión de poco más de 1000000 de dólares que no llevaba a ningún sitio (Rippy, 1981).

Una vez que se tuvo noticia de esto en Nueva York, las acciones de la compañía se desplomaron rápidamente. Sin embargo, por fortuna, dos vapores que iban rumbo a California, el Georgia y el Philadelphia, tuvieron que refugiarse del mal tiempo en la bahía, donde desembarcaron cerca de 1000 mineros en la isla de Manzanillo y no en la desembocadura del Chagres. Los mineros al ver el ferrocarril solicitaron comprar boletos para cruzar el istmo. Esto le presentaba inconvenientes mayores a Totten, pues además de los problemas financieros que estaba enfrentando, veía en estos 1000 mineros un problema adicional de logística para la construcción, razón por la que cobró la elevada cantidad de 50 centavos por milla y tres dólares por cada 100 libras de equipaje, condiciones que para su sorpresa fueron aceptadas sin problema. Esto tuvo un efecto decisivo en la construcción del ferrocarril, pues no sólo se obtuvieron ingresos por 7000 dólares, sino que la noticia elevó el precio de las acciones en Nueva York y se pudo continuar con la obra sin escasez de recursos (Board of Directors \& Totten, 1853, pp. 3-16).

En 1855 las brigadas de construcción que avanzaban desde los dos frentes se encontraron, y para finales de enero entró en funcionamiento el primer tren interoceánico y transcontinental de la historia. La extensión total era de 47.5 millas, con una inclinación de $1.14 \%$, lo que brindaba las condiciones más favorables para atravesar el continente entre Nicaragua y el Darién. La obra tuvo un costo total de 6564552 dólares (Hull, 1999, pp. 13-15).

La inauguración se realizó el 28 de enero de 1855, mientras José de Obaldía, uno de los tres panameños en ocupar la primera magistratura, ejercía la vicepresidencia de Nueva Granada. Con la terminación de la línea el poblado de San Lorenzo perdió toda importancia y el negocio que habían mantenido por largo tiempo los indios canoeros desapareció por 
completo, pues los barcos desembarcaban en la isla de Manzanillo en el inicio de la ruta férrea. ${ }^{4}$

Los pasajes de primera clase se fijaron en 25 dólares, los niños menores de doce años pagaban 6.25 dólares, los pasajes de segunda clase eran de diez dólares, el equipaje personal se cobró a cinco centavos por libra y el expreso a 1.80 dólares por pie cúbico (Hull, 1999, p. 17). Sin embargo, los primeros problemas de infraestructura se presentaron al poco tiempo, pues las traviesas de pino originales se pudrieron por las duras condiciones del trópico. Estas debieron ser reemplazadas por traviesas de guayacán traídas desde Cartagena, las cuales eran tan duras que debían ser taladradas antes de poder incrustar los clavos en ellas.

En este contexto, durante la construcción surgieron algunos hechos que pudieron generar las primeras alarmas sobre la posible pérdida de soberanía sobre el istmo, pero no lo hicieron. En primer lugar, en un artículo publicado por el Panama Herald and Star en 1852, firmado anónimamente por un abogado de la compañía, pero que de acuerdo con McGuinness (2008, p. 74), por la argumentación y el estilo parece de autoría de Totten, se aseguraba que en el contrato firmado con Nueva Granada se otorgaba a la compañía el derecho a promulgar sus propias leyes y regulaciones municipales para la ciudad de Colón, así como el derecho a establecer su propia fuerza pública y cortes independientes a las de Nueva Granada (Bristow, 1906, p. 9). Estas afirmaciones son falsas, ya que el contrato establecía de manera específica que el ferrocarril y la zona de tránsito permanecían bajo soberanía nacional.

En segundo lugar, el 20 de marzo de 1854 algunos ciudadanos estadunidenses y otros extranjeros en Colón establecieron un "comité de vigilancia" que aseguraba estar por encima del poder judicial de la provincia. Esta organización reclamaba que, frente a las fallas del gobierno local, ellos tenían el derecho moral y la obligación de re-establecer el orden público por mano propia (McGuinness, 2008, p. 74). Esto generó algunas preocupaciones desarticuladas que no trascendieron.

Simultáneamente a la existencia del comité de vigilancia, Totten organizó una fuerza de policía privada conocida como el Isthmus Guard, comandada por el ex ranger de Texas Ran Runnels, cuyo fin era disciplinar a los trabajadores que desafiaran la autoridad de la compañía y controlar el bandidaje a lo largo de la ruta; su cargo mensual era de 1000 dólares (Tomes, 1855, pp. 123-124). La financiación de la guardia se hizo a través de fondos de la compañía y de las compañías de navegación asociadas; el 21 de julio de 1854 el gobernador José María Urrutia Añino autorizó ofi(1867)

${ }^{4}$ Narraciones sobre este proceso de declinación pueden encontrarse en Tomes (1855) y Otis 
cialmente dicha guardia. Esta actuaba sin ningún control por parte de las autoridades locales, frecuentemente obtenía información de la población local por medio de sobornos, por la fuerza o con pagos y se tienen registros de que, al menos en una ocasión, la guardia colgó de forma sumaria a sus víctimas en las fortificaciones de la ciudad de Panamá (McGuinness, 2008, p. 76). Aunque la guardia eventualmente fue disuelta en marzo de 1855, al terminar la construcción de la ruta y la disolución abrupta del comité, es importante anotar que esta no fue una imposición unilateral de la compañía o un proyecto explícito del gobierno de Estados Unidos por minar la soberanía nacional, sino fruto de colaboración transaccional, aunque asimétrica, entre el gobierno local y la empresa.

Esto se dio en medio de un intenso debate sobre el tipo de gobierno adecuado para lo que se denominaría "zona de tránsito", la cual era considerada estratégica para el flujo internacional de hombres y mercancías. En febrero de 1855 se creó el Estado federal soberano de Panamá, siendo el primero de los estados del régimen federal. Para regular los negocios de la nación en el Estado de Panamá se promulgó la ley del 24 de mayo de 1855 en la que se especificaba que no se podía hacer ninguna modificación o innovación de ningún tipo al contrato del ferrocarril por parte de Panamá, mismo que quedaba bajo la dependencia exclusiva del gobierno nacional (Montañez, 2003).

Es relevante que estas situaciones reforzaban la idea de territorialidad panameña, ajena a la que pretendía mantener el gobierno colombiano sobre el istmo y que se asentaba sobre nociones anteriores. Este proceso puede verse en un contexto más amplio en la creación de la Gran Colombia tras la independencia y su posterior disolución en tres naciones independientes: Colombia, Venezuela y Ecuador; las diferentes transformaciones del modelo de Estado-nación que tiene Colombia desde la Confederación Granadina hasta la república de Colombia y, por supuesto, la eventual separación de Panamá en 1903.

$\mathrm{Al}$ margen de estos procesos se evidencia que la gran demanda de este ferrocarril lo convirtió por un tiempo en uno de los más rentables del mundo (McGuinness, 2008). A pesar de lo desigual de la concesión y de las condiciones poco favorables para Colombia, en todo caso no fueron para nada despreciables las sumas que ingresaron a las finanzas públicas, convirtiéndose, como se verá más adelante, en uno de los recursos fiscales más importantes de la nación.

\section{INTERESES EXTRANJEROS EN PANAMÁ}

Los intereses de Estados Unidos en el resto de América fueron objetivos estratégicos desde muy temprano. Una de sus primeras expresiones fue la 
doctrina Monroe, diseñada durante la presidencia de John Quincy Adams y presentada al Congreso por el presidente James Monroe en 1823 (Bassett, 1928, p. 31). Sus tres principios básicos eran: primero, las potencias europeas no tienen derecho a intervenir en los asuntos de los Estados americanos; segundo, toda intervención será considerada como un acto hostil por Estados Unidos, y tercero, la fundación de colonias es inadmisible en el continente americano (Collins, 1924, p. 37). El corolario más popular de dicha doctrina es el de "América para los americanos", aunque en la práctica se aplicó en su sentido más restrictivo.

Un hecho fundamental que llevó a esta proclamación fue que tras los procesos de independencia política latinoamericanos aún existían fuertes lazos de dependencia económica con los Estados europeos; dicha dependencia era vista con recelo por Estados Unidos (Loria, 1914, p. 130). La declaración fue recibida cálidamente en toda Latinoamérica, incluso Colombia propuso que fuera ratificada en el Congreso de Panamá de 1826, llamándola "el evangelio del nuevo continente" (Collins, 1924, p. 37). Desafortunadamente, una doctrina internacional es tan fuerte como su más débil interpretación, y la misma Colombia habría de sentir los efectos de la doctrina Monroe sobre Panamá a lo largo del siglo XIX.

Mediante esta política exterior, Estados Unidos asumió paradójicamente el derecho a mediar en las relaciones entre los Estados europeos y los americanos por medio de una declaración que sostenía el principio de no intervención, y al mismo tiempo llevaba a ejercer el derecho a intervenir en los asuntos latinoamericanos (Pillet, 1914, p. 132). Dichas intervenciones ocurrieron a lo largo del siglo XIX y principios del XX en México, Puerto Rico, Nicaragua, la guerra hispano-americana, Haití y Panamá, entre otros.

Una de las primeras señales de alarma sobre la soberanía colombiana en el istmo, al menos para políticos colombianos como Miguel Samper entre otros, comenzó en 1856 y sólo terminaría diplomáticamente en 1869. El hecho, que se conocería como el Incidente de la Sandía, y ocurrió el 15 de abril de 1856; unos 940 pasajeros del buque John L. Stephens esperaban en el puerto de Colón a que la marea cambiara para continuar el viaje hacia Estados Unidos, cuando se escucharon unos disparos (Pérez, 2007, p. 166).

Las versiones sobre el suceso son contradictorias y suelen exagerar los méritos y las culpas de cada uno de los participantes. Lo que sí es claro es que un ciudadano estadunidense en medio de una borrachera se negó a pagar diez centavos por una tajada de sandía al frutero José Manuel Luna; luego de un airado reclamo por parte del último, el estadunidense sacó su arma y disparó, ocasionando una fuerte reacción de pasajeros y lugareños, quienes asaltaron el hotel donde se refugió el agresor, situación 
que terminó con un saldo trágico de muertos y daños a las propiedades de extranjeros (Pérez, 2007).

La respuesta del gobierno de Estados Unidos fue exagerada, ya que procedió al envío de los barcos de guerra Independence y St. Marys; el 19 de septiembre de 1856, 160 marines desembarcaron para ocupar durante tres días la estación del ferrocarril. Esta acción, a más de cinco meses de haber ocurrido el incidente, hizo efectiva la cláusula 35 del tratado Mallarino-Bidlack. Este hecho exacerbó las ya duras críticas y discusiones en Colombia sobre el contenido de este tratado (Pérez, 2007).

Las exigencias estadunidenses para solucionar el problema fueron desproporcionadas. Primero, exigían que Panamá y Colón se convirtieran en ciudades libres, cuyo gobierno tendría una jurisdicción de varias millas de ancho con la línea férrea como eje; segundo, la cesión de las islas en la bahía de Panamá a Estados Unidos; tercero, la transferencia de los derechos sobre el ferrocarril de Nueva Granada a Estados Unidos, y cuarto, el pago de una indemnización de 2000000 de dólares por las vidas perdidas. La disputa diplomática tardó alrededor de diez años en ser solucionada y al final Colombia tuvo que pagar la injusta cantidad de 412394 y 142637 dólares de intereses, amparados en el protocolo Herrán-Mack de 1857.

En medio de estas discusiones ocurrió un cambio político interno de mayor importancia, pues en agosto de 1867, como consecuencia de la transformación de Nueva Granada en Estados Unidos de Colombia, se dio por terminada la concesión por 49 años y se inició una nueva negociación con los inversionistas estadunidenses. Esto ocurrió poco antes del cumplimiento del plazo de 20 años de funcionamiento, al término de los cuales la nación podía hacer uso del derecho de compra por 5000000 de dólares. A pesar de que nadie en el mundo dudaba de que el país haría uso de este derecho, Totten logró hacer un exitoso cabildeo en la capital, exagerando los peligros financieros que enfrentaba la empresa y, aprovechando la debilidad fiscal, forzó la firma de un nuevo contrato en 1867 (Lemaitre, 2007). ${ }^{5}$

La nueva negociación tuvo algunas diferencias importantes, entre las cuales estaban la ampliación del término a 99 años; el pago de 1000000 de dólares y una anualidad por 250000 dólares al gobierno colombiano; además del transporte de tropas, oficiales con equipaje, munición, armamento y otros productos sin cargo por parte de la compañía.

Estos recursos representaban alrededor de 9\% de los recursos fiscales de Colombia, que sumados con los ingresos por los impuestos de aduanas (54\% aproximadamente) y el monopolio de las salinas (27\% aproxima-

\footnotetext{
${ }^{5}$ De acuerdo con la legislación del momento, por las características de la línea, el acuerdo de concesión era firmado por el gobierno nacional y no por el Estado soberano de Panamá.
} 
damente) representaban usualmente 90\% de los ingresos fiscales del país (Deas, 1982, p. 311). En especial, las anualidades pactadas desempeñarían un papel central en el establecimiento y financiación del Banco Nacional durante la administración de Rafael Núñez, pues se contrató un préstamo de 2500000 dólares, otorgado al gobierno por la empresa Morton, Blis \& Company de Nueva York, para establecer buena parte del capital necesario para su instauración (Hernández, 2001, p. 63).

Adicionalmente, el nuevo contrato de concesión eliminó la restricción que tenía el país para otorgar privilegios de construcción de carreteras y de un canal en el istmo. A pesar de esta modificación, se permitió una cláusula mediante la cual se protegían los intereses del ferrocarril, puesto que si el canal se construía en el eje Panamá-Colón, se indemnizaría a la compañía.

Esta situación se combinó con un cambio en las condiciones de competitividad que enfrentaba la línea a partir de la apertura del Central Pacific-Union Pacific, en 1869 , pues la pérdida de mercado repercutió en los resultados financieros. Incluso, para 1877 los ingresos del ferrocarril fueron de 1284000 dólares, mientras que los gastos operativos eran de 998 000, para una ganancia de apenas 286000 dólares, lo que provocó una caída fuerte de las acciones en Wall Street, las cuales, tras haberse cotizado en un pico de 369 dólares por acción en 1874, pasaron a 52 dólares en 1876 (Hull, 1999, p. 18) (véase cuadro 1).

Ante la pérdida de presencia en el mercado y la eliminación de los derechos de exclusividad para la construcción de un canal interoceánico que había mantenido la Panama Railroad Company, los franceses comenzaron a discutir la posibilidad de iniciar la obra. Primero, en el Congreso de Geografía reunido en París en 1875 se decidió que era necesaria una nueva expedición, para lo que se fundó una sociedad de exploración, además de conseguir los fondos necesarios. Los oficiales navales Armand Reclus y N. B. Wyse y el ingeniero M. Celler fueron enviados a investigar la zona y a juzgar los méritos relativos de las distintas regiones. Después de tres años regresaron a París y sometieron al Congreso de 1879 diferentes esquemas, y se decidió que la mejor ruta posible era Colón y la ciudad de Panamá (Lesseps, 1886, pp. 517-518).

Mientras se conocían los resultados de esta expedición, Ferdinand de Lesseps y otros socios fundaron en París la Société Internationale du Canal Interocéanique (luego Compagnie Universelle du Canal Interocéanique) con un capital de 214000000 de francos. Una vez que se supo de los resultados favorables de la misión del Congreso de 1879, De Lesseps comenzó a acumular importantes cantidades de suministros en Panamá, con un efecto inesperado para la línea férrea, que obtener un aumento importante de carga transportada (Hull, 1999, p. 19). 
CUADRO 1. RESULTADOS OPERACIONALES (DÓLARES)

\begin{tabular}{lrrrr}
\hline Años & \multicolumn{1}{c}{ Ingresos } & \multicolumn{1}{c}{ Gastos } & Utilidad & Pagos a la nación \\
& & & & \\
1852 & 250162 & 73999 & 176163 & 4403 \\
1853 & 322428 & 113950 & 208478 & 6143 \\
1854 & 453572 & 116542 & 337030 & 5562 \\
1855 & 1099069 & 284156 & 814913 & 14895 \\
1856 & 1360731 & 530249 & 830492 & 27040 \\
1857 & 1305819 & 649302 & 656518 & 27310 \\
1858 & 1506076 & 858589 & 847388 & 27802 \\
1859 & 1925444 & 795748 & 1129696 & 27892 \\
1860 & 1550876 & 702889 & 847987 & 27914 \\
1861 & 1539860 & 611663 & 928197 & 27923 \\
1862 & 1712281 & 729850 & 983331 & 27966 \\
1863 & 2027438 & 829747 & 1197691 & 29498 \\
1864 & 2489222 & 1029769 & 1459453 & 34000 \\
1865 & 2175885 & 1002051 & 1173834 & 38800 \\
1866 & 2424978 & 1208365 & 1216613 & 45700 \\
1867 & 2717393 & 1183785 & 1533607 & 131500 \\
1868 & 3810192 & 1873114 & 1937079 & 250000 \\
1869 & 2299252 & 1501446 & 797811 & 250000 \\
1870 & 1383450 & 1063218 & 320232 & 250000 \\
1871 & 1883885 & 1084000 & 800000 & 250000 \\
\hline
\end{tabular}

Fuente: elaboración con base en Pérez (2007, p. 164).

Sin embargo, las tarifas de los fletes resultaban demasiado altas para la compañía francesa, y De Lesseps decidió comprar más de 98\% de las acciones (68 887 de las 70000 disponibles) de la Panama Railroad Company. Las acciones se dispararon de unos 60 dólares por acción a 291 dólares, para un total aproximado de 25000000 de dólares (93000 000 de francos), pero aun así resultaba más barato que pagar los fletes. No deja de ser interesante notar que el valor en libros de la compañía era de 1500000 dólares, pero los derechos de exclusividad les dieron la ventaja en la negociación.

Para 1886 la línea transportó 320928 toneladas de carga (su pico más alto), además de movilizar un número récord de 799264 personas. De Lesseps tuvo la intención de trasladar la sede a París, pero las regulaciones de la compañía al momento de su fundación en 1849 lo hicieron imposible, por lo que tuvo que mantener las reuniones oficiales de la 
misma en Nueva York, a pesar del control francés que se tenía sobre esta (Hull, 1999, pp. 19-20).

Esto generó temor en Estados Unidos, ya que la posibilidad de perder el control sobre un futuro canal interoceánico y el hecho de haber perdido ya el control de la línea férrea generaban debilidades militares estratégicas que no podían dejar de tener en cuenta, no obstante la compañía de construcción del canal se había declarado en bancarrota y cesado trabajos para 1889, aunque la línea férrea seguía operando.

El final de la Compagnie Universelle du Canal Interocéanique no pudo ser más triste. En sus últimos años, De Lesseps estuvo inmerso en un penoso proceso judicial que terminó con una condena a dos años de prisión, al igual que su hijo Charles. Incluso Gustave Eiffel también estuvo condenado a dos años por el mismo proceso, que se fundamentó en la pérdida financiera que tuvieron los 800000 inversionistas que habían comprado los bonos de la compañía. Este escándalo financiero llegó a las más altas esferas del gobierno francés y provocó la caída del gabinete del presidente Sadi Carnot, además de que afectó la reputación del importante político Georges Clemenceau (Pérez, 2007, p. 183).

Luego de estos penosos sucesos, los liquidadores de la Compagnie Universelle du Canal Interocéanique lograron, después de un difícil proceso con los activos remanentes de la compañía, la constitución de una nueva empresa: Compagnie Nouvelle du Canal. Esta sociedad tenía un capital suscrito de 65000000 de francos (13000 000 de dólares) dividido en 650000 acciones, de las cuales 7.69\% era considerado como un pago a favor de Colombia a cambio de ratificar los antiguos contratos y privilegios. El resto de las acciones fue adquirido por Gustave Eiffel, Philippe Bunau Varilla y algunos de los acreedores (Pérez, 2007).

Así, el patrimonio de la compañía quedó constituido por los activos remanentes que aún existían en Panamá y, por supuesto, la Panama Railroad Company. Sin embargo, para los inversionistas lo más importante eran los derechos exclusivos de construcción del canal. La dirección del Ferrocarril de Panamá estuvo a cargo de William Nelson Cromwell, quien además tenía alguna participación accionaria (Pérez, 2007).

Simultáneamente, el gobierno de Estados Unidos seguía insistiendo en la firma de un tratado con Colombia para construir un canal; sin embargo, a lo largo de 1901 el gobierno colombiano dilató constantemente cualquier respuesta, y José M. Marroquín, como vicepresidente, se opuso permanentemente a cualquier iniciativa en este sentido. Actitud que se veía en Estados Unidos como una muestra de la corrupción reinante en Bogotá.

Además, el embajador en Washington, Carlos Martínez Silva, fue retirado por el gobierno debido a su posición política. Su reemplazo fue José Vicente Concha. Como directriz del canciller Abadía Méndez, Concha 
exigió al gobierno estadunidense la suma de 20000000 de dólares por rescindir el contrato con los franceses.

Para Estados Unidos y sus intereses en Panamá esta situación se hizo más preocupante a medida que ocurría la guerra de los Mil Días (18991902) en Colombia. Este enfrentamiento fue la máxima expresión de las tensiones entre el liberalismo y el gobierno conservador de la regeneración, y se convirtió en la más cruenta y violenta de las guerras civiles del siglo XIX. Las principales zonas en las que se vivió el conflicto fueron las del oriente cafetero, pero el departamento de Panamá no estuvo aislado de la misma, lo que se vio exacerbado por las viejas intenciones separatistas panameñas.

Debido a todas estas situaciones, el Naval War College, durante el curso de verano de 1901, practicó un "escenario hipotético" en el Caribe bajo los supuestos de que, primero, Alemania había tomado el control de la mayoría de las acciones en la compañía que poseía los derechos de construcción del canal y de manejo del Ferrocarril de Panamá; segundo, que se encontraba en construcción un canal en Nicaragua por parte de Estados Unidos y, tercero, que una insurrección había estallado en Colombia y los insurgentes habían tomado control de la provincia de Panamá. Los juegos de guerra consistían entonces en diseñar las mejores estrategias para evitar la toma de lugares estratégicos para Estados Unidos, que incluían, además de Panamá, Cuba y Puerto Rico (Turk, 1974, p. 92).

Para 1901 la compañía que poseía los derechos de construcción del canal y de manejo del Ferrocarril de Panamá no era alemana sino francesa. Aunado a esto, un par de años atrás estalló una importante insurrección en Colombia durante la cual "los insurgentes" habían tomado control de Panamá. De tal manera, los "supuestos" ya estaban ocurriendo cuando se diseñaron estos juegos de guerra. ¿Coincidencia?

Terminados los juegos de guerra, las conclusiones iniciales del almirante John Hay fueron que la fuerza naval estadunidense debía tomar el istmo de Panamá, Cartagena y la zona en la frontera entre Panamá y Costa Rica. En previsión de lo que pudiera suceder, se comisionó al capitán Thomas Perry del USS Iowa para evaluar la mejor manera de proteger los intereses estadunidenses en Panamá, en especial la forma más expedita para proteger y retener el control del ferrocarril. Asimismo, el Departamento de Estado solicitó sin éxito a Colombia, por medio de su canciller, la cesión de un territorio en el istmo para construir una base militar (Turk, 1974).

En enero de 1903, luego de fuertes presiones por parte de Estados Unidos, se firmó el tratado Herrán-Hay, el cual le concedió a este país el derecho a construir un canal y ocupar temporalmente una faja de terreno de cinco kilómetros de ancho en cada costado del eje de la longitud total del 
terreno que ocuparía el canal; a cambio, Colombia recibiría una compensación de 10000000 de dólares (Pérez, 2007, p. 189).

El Congreso de Estados Unidos aprobó en dos meses este tratado, pero el Congreso colombiano lo recibió con una actitud negativa y dilató las discusiones sobre el tema, a pesar de las vehementes reclamaciones que realizaron las autoridades de la ciudad de Panamá. Debido a esta actitud, el embajador estadunidense en Colombia, Arthur M. Baupré, envió una amenazante comunicación al Congreso colombiano para instarlo a que se aprobara el tratado o Colombia sufriría las consecuencias. Bajo la bandera de un nacionalismo a ultranza, tanto Marroquín como Miguel A. Caro se opusieron con éxito a que el Congreso aprobara el tratado (Pérez, 2007).

Este resultado fue recibido con gran molestia en Estados Unidos y, tras la experiencia obtenida en los juegos de guerra de 1901 y en la medida en que las intenciones secesionistas panameñas cobraron fuerza, se ordenó que las naves de guerra Nashville, Maine, Boston, Wyoming, Concord, Marblehead, Dixie y Atlanta fueran movilizadas para ubicarse sobre las dos costas entre Colombia y Panamá (Turk, 1974, p. 93). Aunque no existe evidencia sólida que indique un plan premeditado del gobierno de Theodore Roosevelt con Philippe Buneau-Varilla (Turk, 1974), los testimonios de la época sugieren lo contrario (El Colombiano, Información, 1903). Buneau-Varilla era miembro de la junta secesionista y uno de los grandes accionistas de la Compagnie Nouvelle du Canal, y su representante en Washington (Cavalier, 1960, p. 11).

Un artículo de 1903 de El Colombiano, que reproduce apartados de otro artículo publicado en Estados Unidos por The World, muestra que tras las acciones de Buneau-Varilla estaban las acciones de un "sindicato de especuladores" de París y Nueva York que crearon un fondo para negociar con las acciones y otros valores de la Compagnie Nouvelle du Canal. El sindicato mencionado reunió dinero para el partido secesionista en Panamá para realizar el movimiento (El Colombiano, Panamá, 1903).

Asimismo, la cabeza visible de dicho sindicato, Maurice Buneau-Varilla, hermano de Phillipe, era redactor de Le Matin, periódico parisiense. Gracias a sus actividades, las acciones del canal pasaron de cotizarse a 67 francos en la bolsa de París a 115 francos. Las utilidades del sindicato, para enero de 1903, se estimaron en 4000000 de francos (El Colombiano, Panamá, 1903).

El 2 de noviembre de 1903 el capitán del Nashville recibió un cable del cónsul estadunidense Oscar Malmros donde lo instaba a mantener un tránsito libre a través de Colón y a que previniera el desembarco de cualquier fuerza armada con intenciones hostiles, fuera del gobierno colombiano o insurgente, en Colón, Portobelo o en cualquier otro punto. Cables 
similares fueron enviados a los buques Boston y al Marblehead, que para entonces se encontraban en las inmediaciones de Panamá, pues los otros buques arribarían después del 5 de noviembre (Turk, 1974, p. 94).

Estas órdenes se llevaron a cabo el 2 de noviembre, cuando, después de permitir el arribo de 400 hombres del ejército colombiano el día anterior, se procedió a desembarcar tropas estadunidenses en Colón, tras lo cual el comandante del contingente colombiano, el coronel Eliseo Torres se vio obligado a reembarcar a sus hombres en el Cartagena el 5 de noviembre. El 6 de noviembre el gobierno de Estados Unidos reconoció la independencia de Panamá. Es importante anotar que el superintendente del ferrocarril pertenecía al movimiento secesionista y que logró mediante engaños que sólo unos cuantos hombres del coronel Torres lo utilizaran para dirigirse a la ciudad de Panamá, el resto permaneció en Colón ( $E l$ Colombiano, Silencio, 1903).

Por otra parte, el superintendente, mister Spaller (El Colombiano, Información, 1903), mediante mentiras sobre el estado de las vías y la posibilidad de transporte indujo a los generales colombianos Juan B. Tovar y Ramón G. Amaya, jefes del ejército del Atlántico, a continuar en la ciudad de Panamá, y negó el paso a las tropas que debían mantener la soberanía colombiana en el istmo. El resultado final fue lamentable: aprisionamiento temporal de los militares mencionados y otros magistrados leales al gobierno central (El Colombiano, Silencio, 1903).

El presidente Roosevelt ordenó al ejército y a la fuerza naval preparar los planes necesarios para evitar que Colombia lograra evitar la secesión de Panamá, para lo cual se estableció una directiva mediante la que se estableció un bloqueo efectivo sobre las costas del Pacífico y el Caribe colombianos y se dispusieron para ocupar los puertos de Cartagena, Santa Marta, Sabanilla y Buenaventura. En todo caso, para evitar el inicio de cualquier hostilidad, se evitó que el contraalmirante y comandante en jefe de las escuadras en el Caribe, J. B. Coghlan, realizara una "visita" planeada de dos años antes al puerto de Cartagena (Turk, 1974, p. 94).

Por supuesto, para las maltrechas tropas colombianas, tras la guerra de los Mil Días y la penosa situación fiscal, resultó imposible emprender cualquier operación para recuperar el territorio panameño, que en términos prácticos era más un territorio insular que parte integral del país. La separación generó una difícil situación diplomática entre los gobiernos colombiano y estadunidense que tardaría muchos años en terminar.

En todo caso, el presidente Roosevelt ordenó que el USS Prairie partiera el 11 de diciembre de 1903 con un batallón de marines para fortalecer la seguridad en Colón y la línea férrea. Poco tiempo después arribaron dos batallones de marines del USS Dixie para reforzar las tropas desembarcadas a lo largo del ferrocarril. Una vez desplegadas, se formó oficialmente 
una brigada provisional en Panamá para defender los intereses del gobierno estadunidense (Hendrix, 2006).

En 1904, tras el reconocimiento de la independencia de Panamá, el gobierno de Estados Unidos aprobó la Ley Spooner del 28 de junio de 1902, la cual autorizó al presidente Roosevelt para comprar los bienes de la compañía francesa en Panamá; este adquirió por 40000000 de dólares los derechos, privilegios, franquicias, concesiones, cesiones de tierras, derecho de tránsito, obras inconclusas, maquinaria y bienes raíces que la Compagnie Nouvelle du Canal, de nacionalidad francesa, poseía en Panamá, con todos sus mapas, planos, dibujos y archivo en el propio istmo y en París (Novoa, 1903). Además, se firmó el tratado Buneau-Varilla-Hay, el cual concedió vía libre a la construcción del canal en territorio panameño.

Esta compra incluyó 4000 acres de tierra incluidos en la primera concesión del ferrocarril que prácticamente abarcaban el territorio de Colón, terrenos que supuestamente debían regresar a Colombia al final del tiempo de la concesión. Al firmarse los respectivos tratados entre Estados Unidos y Panamá, se reconoció que la propiedad de los terrenos se revertiría a este último país (Novoa, 1903).

De esta manera, el gobierno de Estados Unidos obtuvo la mejor tierra panameña, aunque no podía disponer de ella durante los 99 años de la franquicia, que seguiría vigente hasta 1966. No obstante, la Panama Railroad Company cobró importancia como un exitoso agente de bienes raíces al poner estas tierras en el mercado por medio de contratos de arrendamiento que se subastaban al mejor postor sin restricciones de tiempo. Además, mediante tratados entre los dos gobiernos, Estados Unidos consiguió una zona canalera de diez millas de ancho en cada total a través del istmo. De acuerdo con Peter M. Sánchez (2002), estas concesiones son las más generosas otorgadas en cualquier tratado moderno y, prácticamente constituyó la formación de un Estado dentro de otro Estado (pp. 57-64).

La propiedad de la compañía fue trasladada al gobierno de Estados Unidos junto con 48 millas de líneas férreas y 26 millas de vías de cambio y patios, 35 locomotoras, 30 carros de pasajeros, 900 vagones de carga. La mayoría de estos equipos eran obsoletos o estaban deteriorados e inservibles. Las locomotoras y los vagones se encontraban diseminados a lo largo de la vía y muchos de ellos habían sido tomados por la vegetación local (Hull, 1999, pp. 20-22).

En mayo de 1904 el presidente Roosevelt creó la Comisión del Canal Ístmico para construir el canal, que debía recorrer buena parte de la línea férrea, para lo cual se hacía necesaria una reubicación completa de los rieles al sur de Gatún; de esta manera, se puso bajo su jurisdicción el ferrocarril. En 1905 se inició un programa de recuperación del sistema, 
transformándolo en una línea de doble vía que fue fundamental en la construcción del canal. El trazado se reubicó hacia una zona más alta a partir de 1907, para seguir con las obras con un costo de 9000000 de dólares y una duración de cinco años y que finalizaron en 1912 (Hull, 1999).

De esta manera, Estados Unidos controló de forma directa el mar Caribe desde Florida, pasando por Guantánamo en Cuba y por Puerto Rico, hasta el valioso paso a través de Panamá, haciendo valer el octogenario corolario de "América para los americanos".

\section{CONSIDERACIONES FINALES}

La obra del ferrocarril fue sin duda una de las empresas más importantes en términos de infraestructura que se construyó y operó en Colombia durante el siglo XIX. Aunque las condiciones de las diferentes concesiones fueron desventajosas para Colombia, en todo caso tuvieron un significativo impacto fiscal para el gobierno, que dadas sus condiciones financieras difícilmente hubiera podido construirlo por cuenta propia.

Durante sus mejores años, la empresa fue una de las más rentables del mundo, incluso llegó a repartir dividendos, en 1867, por una cifra récord que ascendió a 44\%, aunque en 1868 bajó a 20\%. Los años siguientes no fueron tan favorables, y se registró un pico muy bajo en 1870, de tan sólo 3\%, para nivelarse entre 9 y 16\% en los seis años siguientes (Lemaitre, 2007).

Durante muchos años la Panama Railroad Company transportó casi la totalidad del oro que se extrajo en California, llegando a registrarse entre 1855 y 1867 un total de 700000000 de dólares en oro transportado, sin que se reportase un solo robo o pérdida durante estos años. Bajo el control francés, la empresa transportó 320928 toneladas de carga y 799264 pasajeros en 1886, cifra récord hasta ese momento (Hull, 1999, p. 18).

En 1913, bajo propiedad del gobierno estadunidense, el ferrocarril transportó 2916657 pasajeros y 2026852 toneladas de carga, con lo que se convirtió en el ferrocarril con el tráfico por milla más pesado del mundo. No obstante, al año siguiente, con la inauguración del canal, el flujo de carga prácticamente desapareció, y sólo continuó transportando carga interna hasta la inauguración de una carretera a través del istmo en 1943 (Hull, 1999).

Si se observa el comportamiento operativo durante la gestión estadunidense, puede considerarse una empresa rentable y, como se dijo, uno de los recursos fiscales más importantes para Colombia.

Sin embargo, el impacto sobre el desarrollo económico de Panamá y de Colombia fue bajo, pues el sistema no fue pensado para articular mer- 
cados internos con el comercio internacional, sino como una vía de paso transoceánico; por otra parte, los materiales necesarios para su construcción fueron importados, salvo las traviesas que reemplazaron a las originales, sin que hubiera efectos de eslabonamiento industrial hacia atrás. De esta manera, los efectos tradicionales en el desarrollo de vías férreas en el mundo no se dieron en este caso.

Por supuesto, la participación de Estados Unidos en la separación de Panamá fue una fuente de tensiones entre aquel y Colombia, que sólo se solucionarían el 6 de abril de 1914 con la firma del tratado UrrutiaThompson. Mediante este tratado, Colombia reconoció en el primero de sus cuatro artículos la propiedad total del canal y del Ferrocarril de Panamá a Estados Unidos a cambio de que este último se comprometiera a permitir el paso de tropas, material y buques de guerra por el canal sin pagar cargos. El paso de correos y de carga colombiana estaría sujeto a los mismos cargos que los de Estados Unidos; asimismo, los ciudadanos colombianos no deberían pagar ningún cargo adicional a lo que los ciudadanos estadunidenses pagaban. En caso de estar bloqueado el canal por cualquier razón, estas mismas condiciones serían válidas para el Ferrocarril de Panamá.

El segundo artículo del tratado contenía el compromiso por parte de Estados Unidos de pagar 25000000 de dólares en oro. Esta indemnización comenzó a pagarse en 1923 y tuvo un impacto enorme sobre las finanzas públicas colombianas, las cuales vivieron un periodo de auge sustentado en este pago y en dos cambios estructurales mayores: el cambio en las condiciones de crédito externo y la bonanza cafetera. El periodo comprendido entre 1923 y 1928 es conocido como la danza de los millones, y se tradujo en importantes tasas de crecimiento económico.

El tercer artículo contenía el reconocimiento final, por parte de Colombia, de Panamá como una república independiente, y se aceptaron las fronteras del departamento como estaban determinadas en la Ley 9 de 1855; además, Colombia se comprometió a establecer las relaciones diplomáticas y económicas con Panamá bajo la supervisión de Estados Unidos.

Es frecuente encontrar en la literatura posiciones encontradas sobre la intervención estadunidense como una muestra clara del imperialismo sobre Latinoamérica. No obstante, la participación de las elites locales fue muy activa, y obtuvo claros beneficios de estas negociaciones. El estudio de casos como el de la Panama Railroad Company no puede limitarse a una visión de la periferia o de la elite local que acepta a la fuerza una política imperialista en contra de su "voluntad nacional", sino que debe comenzar a estudiarse como un caso de múltiples grupos en Latinoamérica que aceptan, resisten, moldean y adaptan esta situación de acuerdo con sus intereses. 


\section{LISTA DE REFERENCIAS}

Arias de Greiff, G. (1986). La mula de hierro. Bogotá: Carlos Valencia Editores.

Bassett-Moore, J. (julio, 1928). The Monroe Doctrine. Annals of the American Academy of Political and Social Science, 96, 31-33.

BoArd of Directors (1849). Panama Rail-Road Company. Nueva York: Van Norden $\&$ Amerman.

Board of Directors \& Totten, G. M. (1853). Communication of the Board of Directors of the Panama Railroad Company to the stockholders together with the report of the chief engineer to the directos. Nueva York: John F. Trow Printer.

BRISTOw, J. L. (1906). Report of the special Panama Railroad Commisioner to the Secretary of War (Office of Administration, Isthmian Canal Affairs). Washington: Goverment Printing Office.

Cavalier, G. (1960). La política internacional de Colombia (1860-1903). Bogotá: Iqueima.

Collins, H. T. (enero, 1924). Misinterpreting the Monroe Doctrine. Annals of the American Academy of Political Science, 111, 37-39.

DEAS, M. (noviembre, 1982). The fiscal problems of the nineteenth century Colombia. Journal of the Latin American Studies, 14(2), 287-328.

Hendrix, H. J. (diciembre, 2006). TR's Plan to invade Colombia. Naval History, 20(7), 36-42.

Hernández, A. (2001). La moneda en Colombia. Bogotá: Villegas Editores.

Horna, H. (2003). Los ferrocarriles latinoamericanos del siglo XIX: el caso Colombia. En C. D. L. DE GuEvara (comp.), Empresas y empresarios en la historia de Colombia. Siglos XIX-XX (vol. II, pp. 1023-1044). Bogotá: Norma/Uniandes.

Hull, G. (1999). Panama's Transcontinental Railroad. National Railway Bulletin, 64(5), 4-35.

Lemaitre, E. (2007). Panamá y su separación de Colombia. Recuperado de www.lablaa.org/blaavirtual/historia/panam/indice.htm

Lesseps, F. DE (diciembre, 1886). The Panama Canal. American Association for the Advancement of Science, $8(200), 517-520$.

Loria, A. (julio, 1914). The Monroe Doctrine. Annals of the American Academy of Political and Social Science, 54, 130-131.

McGuinness, A. (2008). Path of the empire: Panama and the California Gold Rush. Ithaca: Cornell Press.

Montañez, G. (2003). El istmo de Panamá y Colombia: de puente natural a juego geopolítico de la Unión. En H. Bonilla y G. Montañez (eds.), Colombia y Panamá: la metamorfosis de la nación en el siglo XX (pp. 125-154). Bogotá: Universidad Nacional/Convenio Andrés Bello.

Novoa, B. (11 de julio, 1903). Canal de Panamá-Ley Spooner. El Colombiano.

Nott Otis, F. [Oran, 1858] (2004). Panama Railroad. En M. DE LA Rosa y G. MejíA (eds.), The United States discovers Panama: The wrintings of soldiers, scholars, scientist, and scoundrels, 1850-1905 (pp. 15-40). Oxford: Rowman \& Littlefield Publishers Inc. 
PÉrez, G. (2007). Nos dejó el tren: la historia de los ferrocarriles colombianos y los orígenes del subdesarrollo. Colombia: Cisnecolor.

Pillet, A. (julio, 1914). The Monroe Doctrine. Annals of the American Academy of Political and Social Science, 54, 131-133.

Platt, R. S. (marzo, 1926). Central American Railways and the Panamerican Route. Annals of the Association of American Geographers, 16(1), 12-21.

Rippy, F. (1981). El capital norteamericano y la penetración imperialista en Colombia. Bogotá: El Áncora.

SÁnchez, P. M. (septiembre, 2002). The end of hegemony? Panama and the United States. International Journal of World Peace, 19(3), 57-89.

Tomes, R. (1855). Panama in 1855. An account of The Pana Rail-Road and the cities of Panama and Aspinwall with sketches of life and character of the Isthmus. Nueva York: Harper and Borthers.

Turk, R. (octubre, 1974). The United States Navy and the 'Taking' of Panama. Military Affairs 38(3), 92-96.

Weaver, T. (1992). Los indios del Gran Suroeste de Estados Unidos. España: Abya Yala.

\section{OTRAS FUENTES}

\section{Hemerografía}

El Colombiano, 1903. Biblioteca Piloto, en Medellín, Colombia.

Le Matin, Biblioteca Piloto, en Medellín, Colombia.

The World, Biblioteca Piloto, en Medellín, Colombia.

\section{Bibliografía}

Otis, F. N. (1867). History of the Panama Railroad and of the Pacific Mail Steamship Company. New York: Harper \& Brothers. 